\title{
STRESSING STATE CHARACTERISTICS OF REINFORCEMENT CONCRETE BOX-GIRDERS STRENGTHENED WITH CARBON FIBER REINFORCED PLASTIC
}

\author{
Hengheng XIAO ${ }^{1,2}$, Jun $\mathrm{SHI}^{3 *}$, Junran $\mathrm{LIU}^{1,2}$, Kaikai ZHENG ${ }^{1,2}$, Guangchun ZHOU ${ }^{1,2}$ \\ ${ }^{1}$ Key Lab of Structures Dynamic Behavior and Control of the Ministry of Education, \\ Harbin Institute of Technology, 150090 Harbin, China \\ ${ }^{2}$ Key Lab of Smart Prevention and Mitigation of Civil Engineering Disasters of the Ministry \\ of Industry and Information Technology, Harbin Institute of Technology, 150090 Harbin, China \\ ${ }^{3}$ School of Transportation Science and Engineering, Harbin Institute of Technology, 150090 Harbin, China
}

Received 12 June 2019; accepted 26 August 2019

\begin{abstract}
This paper investigates structural performance of five reinforcement concrete (RC) box-girders under a combination loading of bending, shear and torsion, applying the structural stressing state theory. The measured strain data is modeled as generalized strain energy density (GSED) to characterize the structural stressing state mode. Then the MannKendall $(\mathrm{M}-\mathrm{K})$ criterion is innovatively applied to detect the leap characteristics of RC box-girders' stressing state from the $E^{\prime}-T$ curves, deriving the new definition of structural failure load. Furthermore, the reinforcement effects of different Carbon Fiber Reinforced Plastic (CFRP) wrapping schemes on the behaviors of experimental RC box-girders are revealed through comparing strain modes of stirrup and longitudinal reinforcement. Finally, the method of numerical shape function is applied to reasonably expand the limited strain data for further exploring the strain distribution of cross section and analyzing the stressing state characteristics of the RC box-girders. The research results provide a new angle of view to conduct structural analysis and a reference to the improvement of reinforcement scheme.
\end{abstract}

Keywords: stressing state, leap, failure load, stressing state mode, CFRP, reinforcement concrete box-girder.

\section{Introduction}

As a new and effective strengthening material, Carbon Fiber Reinforced Plastic (CFRP) has been widely adopted in civil engineering construction, such as reinforced concrete (RC) structures, steel structures, timber structures and so on for its outstanding fatigue resistance and noncorrosive characteristics (Shahawy, Arockiasamy, Beitelman, \& Sowrirajan, 1996; Orbanich, Dominguez, \& Ortega, 2012; Bousselham \& Chaallal, 2013). Furthermore, the performances of CFRP-strengthened structures or members present significant improvement both in service and ultimate load bearing conditions due to the properties of high tensile strength, high modulus of elasticity, ease of adapting geometry, et al. (Barnes \& Mays, 1999; Aidoo, Harries, \& Petrou, 2004). Therefore, the reinforcement technology of using CFRP is rapidly increasing in the construction filed.

In order to investigate the behavior of strengthened structures or members by CFRP, researchers conducted many valuable experiments after 21th century. For instance, Rafi, Nadjai, Ali, and Talamona (2008) performed an experiment consisting of CFRP and steel bar $\mathrm{RC}$ beams and investigated the bending behavior of RC beams strengthened with CFRP. The results indicated that the behavior of CFRP and steel RC beams was similar in many aspects. Yang, Park, and Neale (2009) tested the flexural bearing capacity of 13 FRP-strengthened RC beams and compared the experimental results with the analytical predictions obtained by finite element (FE) method. The research results showed that the bending capacity of RC beams improved a lot after strengthened by CFRP. Rahai and Saberi (2011) investigated the effects on the flexural behavior of damaged girders strengthened with FRP composed of different fibres and resins. The results reflected the flexural capacity of damaged girders strengthened with FRP significantly improved, while the type of binders had few influences on the reinforcement effect. Besides, Al-zaid, El-Sayed, Al-Negheimish,

${ }^{*}$ Corresponding author. E-mail: hitshijun@hit.edu.cn 
Shuraim, and Alhozaimy (2014) manufactured eight fullscale RC girders to investigate the flexural performance of damaged girders strengthened by CFRP and found that the ultimate bearing capacity and stiffness of models were improved through strengthening with CFRP. In fact, reinforcement with CFRP can not only enhance the flexural capacity of structures or members but the shear capacity. Ali, Samad, Mohamad, and Jayaprakash (2013) studied the shear behavior of CFRP strengthened pre-cracked continuous beams under different wrapping directions through designing one contrast beam and four tested beams. The findings verified that the method of reinforcement with CFRP exerted a tremendous influence on the shear capacity of experimental beams. Samad et al. (2017) conducted an investigation on the shear strengthening of 2-span continuous RC beams strengthened with CFRP strips. And some variables affecting the shear strengthening were analyzed, which included shear span to effective depth ratio, wrapping schemes, numbers of layers of CFRP strips, and CFRP orientation angles. Foster et al. (2017) undertook an experimental study of unstrengthening and CFRP-strengthened reinforced T-beams to investigate the influences on the shear stress capacity of tested T-beams. Fagone and Ranocchiai (2018) proposed an experimental program to analyze the mechanical performance of masonry specimens reinforced with CFRP sheets, loaded by out-of-plane actions. The results showed the shape ratio of specimens played a significant role in affecting the effectiveness of spike anchors. Nair, Cai, Kong, and Hou (2019) used a new FRP-wrapped balsa wood bridge deck to replace the damage deck of a bridge and carried out corresponding experiment to evaluate this composite system, expecting to providing evaluation guidelines for this specially configured FRP-wood deck system. In general, all these researches on the behavior of strengthened structures or members by CFRP further promote the application of CFRP in the field of maintenance and reinforcement in civil engineering (Aidoo, Harries, \& Petrou, 2006; Zhu, Wang, Kang, \& Li, 2016). However, there are still two problems of analyzing structures strengthened with CFRP to be resolved, as summarized below:

- Most researches into the effects of CFRP seem to concentrate on flexural and shear strengthening, while the information on its applicability in torsional strengthening is limited (Pham \& Al-Mahaidi, 2004; Al-Mahaidi \& Hii, 2007; Esfahani, Kianoush, \& Tajari, 2007). In fact, many structures are in intricate stress state and may subject to significant torsion that has non-negligible impact on the design. Therefore, the influences of torsional strengthening are also worth of attention (Jiang, Zhang, \& Tian, 2018). Up till present moment, although some experiments have been conducted to study the change of torsional behavior after strengthened with CFRP, most investigation results were exploratory, making the analytical approach proposed difficult to validate (Hii \& Al-Mahaidi, 2007). In addition, the focus of these researches tends to determine the increment of ultimate torsional bearing capacity after strengthened with CFRP rather than clarifies the changing process of the experimental specimens during the whole loading process.

- Different reinforcement methods could affect the behavior characteristics of the structures strengthened with CFRP. There exist many variables to evaluate the reinforcement effects of CFRP, such as strengthening configurations, the percentage of externally bonded wrap CFRP reinforcement and so on, which need considerable experiments to investigate effects of various factors on the structural performance after strengthened with CFRP (Leung et al., 2007). However, the high experimental expense leads to the insufficient experimental data, which limits the research to revealing the unseen working characteristics of tested structures or members. Moreover, the existing experimental data have not been mined fully, which means an effective analytical method is expected to further explore the effects of different CFRP wrapping schemes on the structural performance.

In consideration of these two issues, the authors investigate a total of five RC box-girders, including one contrast girder without reinforcement and four girders wrapped with CFRP strips. According to the theory of structural stressing state, the measured strains of steel bars in RC box-girders and CFRP strips are modeled as generalized strain energy density (GSED) to describe the box-girders' stressing state modes and the sum of GSED is introduced as characteristic parameter to express the box-girders' stressing state. Then, the leap feature of the tested box-girders' stressing state can be accurately detected through applying the Mann-Kendall (M-K) criterion from $E^{\prime}-T$ curves, resulting in the update of available definition of tested box-girders' failure load. Thus, the effects of different CFRP wrapping schemes on the boxgirders' performance could be revealed through comparing the stressing state modes of box-girders established by the measured strain data. In addition, the characteristics of each strengthening scheme are also revealed through comparing the strain distribution pattern of box-girders strengthened with CFRP and that of contrast box-girder. Finally, based on the method of numerical shape function (NSF), the limited strain data is expanded to further investigate the stressing state characteristic of box-girder. The strain fields obtained by the NSF method could vividly indicate the change of box-girder's stressing state after strengthened with CFRP.

\section{Modeling of structural stressing state and $M-K$ criterion}

\subsection{The concept and function of structural stressing state}

Although the conception of structural stressing state is frequently mentioned in the structural analysis, there is no uniform and precise definition of structural stressing 
state. Hence, according to the mutual variation characteristics presented in the structural working process and the structural performance revealed by classical mechanics, the structural stressing state can be defined as the inner or outer modes of the structure under a certain loading case, which can be characterized by the numerical models of the structural responses, such as strains, deflection, rotation angle, GSEDs, internal forces, etc. (Zhou, Rafiq, Bugmann, \& Easterbrook, 2006). And these numerical models are expressed in the form of matrices and vectors. The structural stressing state mode is generally for the whole structural and the stressing state submodes are for structural members, local components, key points and sections and various types of internal forces.

One primary function of the structural stressing sate theory is to establish corresponding criterion to accurately distinguish the qualitative leap feature through modeling structural stressing state. This qualitative leap feature is verified to comply the natural law from quantitative change to qualitative change of a system and is the common characteristic of various structural failure forms (Shi, Li, Zheng, Yang, \& Zhou, 2018). In addition, this kind of structural failure characteristic also sets up a new theoretical basis to investigate the analytical method of coordinative working of the structure, promoting the rationality of structural design.

\subsection{Modeling of structural stressing state}

As mentioned above, the numerical mode of structural stressing state can be described by the responsive characteristic of the structure. In order to construct the numerical mode expressed in the form of vector or matrix and the corresponding characteristic parameters, generalized strain energy density (GSED) is adopted to numerically present the stressing state of a measuring point (Huang, Y. Zhang, M. Zhang, \& Zhou, 2014). Thus, the GSED can be calculated by Eqn (1):

$$
E_{i j}=\int \sigma_{1} d \varepsilon_{1}+\sigma_{2} d \varepsilon_{2}+\sigma_{3} d \varepsilon_{3},
$$

where $E_{i j}$ is the GSED value of the $i$-th measuring point under the $j$-th load; $\sigma_{1}, \sigma_{2}, \sigma_{3}$ and $\varepsilon_{1}, \varepsilon_{2}, \varepsilon_{3}$ are three principal stresses and strains, respectively.

Therefore, the structural stressing state mode can be formed by the GSED values of all the measuring points in the structure. Correspondingly, the GSED sum of the structure under each load level can be obtained through Eqn (2):

$$
E_{j}^{\prime}=\sum_{i=1}^{N} E_{i j},
$$

where $E_{j}^{\prime}$ is the structural GSED sum of all the measuring key points under the $j$-th load, $N$ is the total number of these points. Then the $E^{\prime}-T$ curve can be plotted to investigate the structural stressing state features, $T$ is the torque applied on the box-girders.

\subsection{The detection of structural stressing state characteristics}

The $\mathrm{M}-\mathrm{K}$ criterion as a nonparametric statistical method is widely used in trend analysis without necessity for samples to comply normal distribution and interference of individual outliers (Mann, 1945; Kendall, 1957; Hirsch, Slack, \& Smith, 1982). In this paper, the M-K criterion is adopted to distinguish the leap characteristic of structural stressing state from the $E^{\prime}-T$ curve. The operative procedures are as follows:

1) For an $E^{\prime}-T$ curve, define cumulative number $S_{i}$ as $S_{i}=\left\{\begin{array}{lr}+1 & E_{i}^{\prime}>E_{j}^{\prime}(1 \leq j \leq i) \\ 0 & \text { otherwise }\end{array}\right.$ in which “ +1 ” means adding one more on the existing value when the $E_{i}^{\prime}$ is greater than $E_{j}^{\prime}$ from the sequence $\left(E_{1}^{\prime}, E_{2}^{\prime}, E_{3}^{\prime}, \cdots, E_{n}^{\prime}\right)$.

2) A new stochastic variable $P_{k}$ is defined as:

$$
P_{k}=\sum_{i}^{k} S_{i},(2 \leq k<n) .
$$

3) The mean value $E\left(P_{k}\right)$ and the variance $V\left(P_{k}\right)$ can be calculated by the following equations:

$$
\begin{aligned}
& E\left(P_{k}\right)=\frac{k(k-1)}{4},(2 \leq k \leq n) ; \\
& V\left(P_{k}\right)=\frac{k(k-1)(2 k+5)}{72},(2 \leq k \leq n) .
\end{aligned}
$$

4) Since the sequence $\left(E_{1}^{\prime}, E_{2}^{\prime}, E_{3}^{\prime}, \cdots, E_{n}^{\prime}\right)$ is statistically independent, define $U T_{k}$ as:

$U T_{k}=P_{k}-E\left(P_{k}\right) / \sqrt{V\left(P_{k}\right)}$.

Thus, the values of $U T_{k}$ are applied to plot the $U T_{k}$-T curve.

5) Then repeat the steps from (1) to (4) to the reverse sequence $\left(E_{n}^{\prime}, \cdots, E_{3}^{\prime}, E_{2}^{\prime}, E_{1}^{\prime}\right)$, which can form the $U B_{k}-T$ curve.

6) Through placing the $U T_{k}-T$ and the $U B_{k}-T$ curves in the same graph, the leap feature of the structural stressing state can be detected by their intersection.

\section{Experimental RC box-girders}

\subsection{Configuration of experimental box-girders}

Yang (2016) conducted the experiment of five singlechamber rectangular RC box-girders with the same section labeled B1, B2, B3, B4 and B5. As shown in Figure 1, the experimental RC box-girder is $3200 \mathrm{~mm}$ in length, $600 \mathrm{~mm}$ in width and $400 \mathrm{~mm}$ in height. The effective length is $3000 \mathrm{~mm}$ with two ends simply supported. Figure 1 (b) shows the section dimension and the placing of steel bars. The experimental RC box-girder is $60 \mathrm{~mm}$ on the web and $80 \mathrm{~mm}$ on the upper plate and bottom slab. The yield stress, elastic modulus and fracture strength of steel bar are $246.14 \mathrm{MPa}, 210 \mathrm{GPa}$ and $315.32 \mathrm{MPa}$, respectively. 
The compressive strength and elastic modulus of concrete are 29.8 MPa and 29.7 GPa. The tensile strength and elastic modulus of the CFRP sheet are $4100 \mathrm{MPa}$ and $235 \mathrm{GPa}$. And the thickness of the single-layer CFRP sheet is $0.1111 \mathrm{~mm}$. Table 1 lists the different approaches of these experimental RC box-girders strengthened with CFRP sheets.

\subsection{Measuring points arrangement}

Strains of longitudinal reinforcement and stirrup are recorded at the mid-span cross section and strains of concrete and CFRP are recorded at the mid-span and L/4 cross sections. Figure 2(a) shows the whole testing arrangement of box-girder. Figure 2(b, c and d) show the specific layout of the strain gauges for strain measurement on the cross sections.

a)

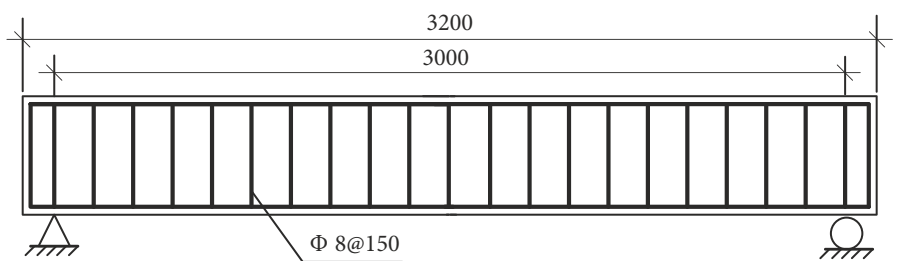

\subsection{Loading scheme}

The torque $(T)$ is exerted through applying concentrated load $\left(F_{1}\right)$ by the jack at the end of self-made experimental device. The concentrated load $\left(F_{0}\right)$ is applied by jack at the mid-span of the experimental RC box-girder, then $F_{0}$ is allocated at three diving point through I-beam, as shown in Figure 3 . In the initial stage, $F_{0}$ and $F_{1}$ are synchronously imposed on the RC box-girder and bending-torsion ratio is 0.38 . After concrete cracking, $F_{1}$ is applied with a fixed increment of $3 \mathrm{kN}$ while $F_{0}$ remains unchanged until the RC box-girder is destroyed. The cracks appear passing through the box-girder, indicating that concrete is out of action and the box-girder is damaged. Figure 3(a) shows the loading apparatus and the distribution of cracks during damage.

Figure 1. Geometric configuration of the experimental RC box-girder (units: $\mathrm{mm}$ ): a - geometric shape and sizes of the RC box-girder; $\mathrm{b}$ - the reinforcement distribution, shape and sizes of cross section

Table 1. The CFRP wrapping schemes of experimental RC box-girders

\begin{tabular}{|c|l|c|c|}
\hline Specimen number & \multicolumn{1}{|c|}{ CFRP wrapping scheme } & Layer number & Schematic diagram \\
\hline B1 & None & Bottom configuration with full CFRP sheet & 1 \\
\hline B2 & U configuration with separate CFRP strips & 1 \\
\hline B3 & U configuration with full CFRP sheet & 1 & Bottom configuration with full CFRP sheet \\
\hline B4 & U configuration with separate CFRP strips & 1 \\
\hline B5 & & \\
\hline
\end{tabular}

a)

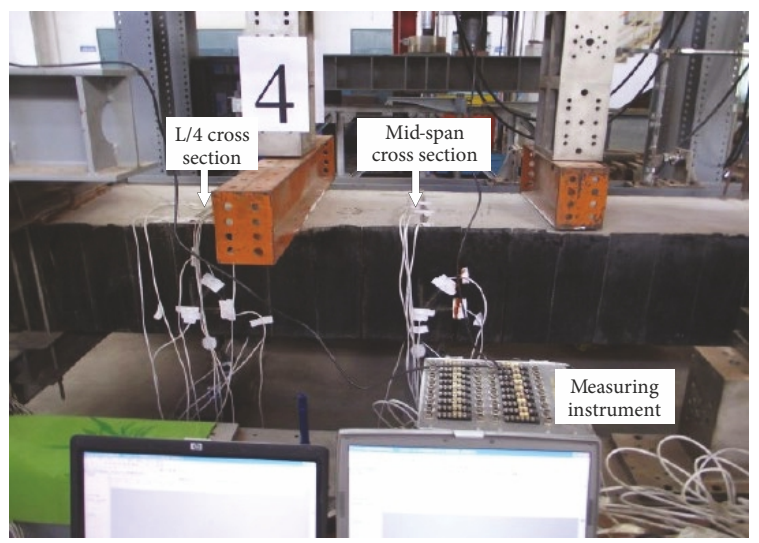

b)

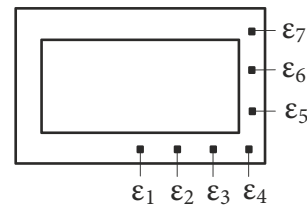

- Longitudinalstrain gauge

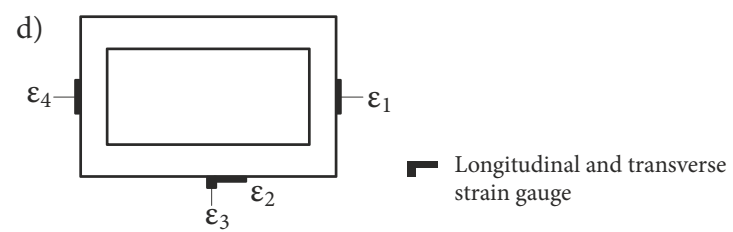

Figure 2. The testing arrangement and layout of strain gauge on the cross sections: a - experimental box-girder and measuring instrument; $\mathrm{b}$ - strain measurement of longitudinal reinforcements on the mid-span cross section; $\mathrm{c}$ - strain measurement of stirrup on the L/4 cross section; $d$ - strain measurement of CFRP on the L/4 cross section 


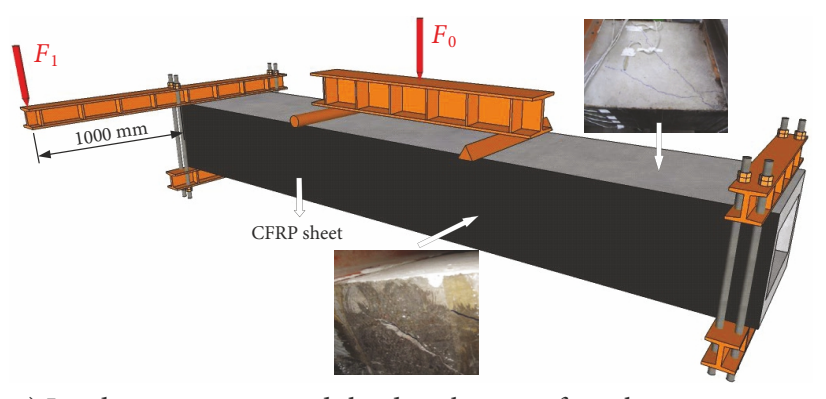

a) Loading apparatus and the distribution of cracks

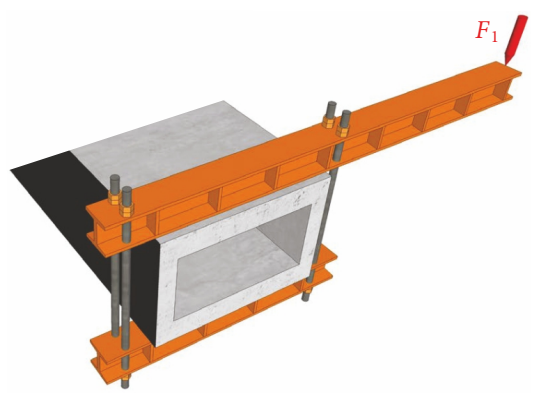

b) The method of applying torque

Figure 3. The simplified model of experimental RC box-girder and loading mode: a - loading apparatus and the distribution of cracks; b - the method of applying torque

In order to clearly exhibit the application of torque, the detailed information of the end section applied torque is given, as shown in Figure 3(b).

\section{Stressing state of experimental RC box-girder}

\subsection{GSED-based structural stressing state and corresponding characteristic parameter}

The GSED values of the measuring points on the midspan cross section are formed a vector to evaluate the stressing state mode of RC box-girder, $\mathbf{S}_{j}=\left[e_{M 1}, e_{M 2}, \cdots\right.$, $\left.e_{M i}, \cdots, e_{M N}\right]^{T}$, in which $e_{M i}$ is the GSED value of the a point among $N$ measuring points at the mid-span cross section of RC box-girder. The corresponding parameter of $S_{j}$ proposed to reveal the RC box-girder's stressing state features is expressed as the sum of the GSED values:

$$
E_{j}^{\prime}=\sum_{i=1}^{N} e_{i j},
$$

where $e_{i j}$ is the GSED value of the $i$-th measuring point to the $j$-th load level; $N$ is the number of measuring point of longitudinal reinforcement and stirrup. Therefore, based on the GSED values, the structural stressing state is modeling by $S_{j}$ and the parameter $E_{j}^{\prime}$ at each load level is proposed to characterize the change of structural performance. Then, the $E^{\prime}-T$ curve can be utilized to investigate the leap features of RC box-girder's stressing state.

\subsection{Investigation into the $E^{\prime}-T$ curve}

For B4 exampled here, the sum of GSED values $\left(E^{\prime}\right)$ under each load can be calculated through Eqn (2), then the $E^{\prime}-T$ curve can be plotted to analyze the behavior of RC box- girder. The two characteristic loads, $P=33 \mathrm{kN} \cdot \mathrm{m}$ (form 0 to ultimate load $U$ ) and $Q=54 \mathrm{kN} \cdot \mathrm{m}$ (from $P$ to $U$ ), are distinguished from the curve using the $\mathrm{M}-\mathrm{K}$ criterion, as shown in Figure 4. The structural stressing state during the whole loading process can be divided into three stages by the two characteristic loads: (1) before the load $P$, the sum of GSED value $E^{\prime}$ increases slowly with load, indicating that the experimental RC box-girder is basically in a linear-elastic state. (2) from $P$ to $Q$, the structure is in an elastic-plastic stressing state with little plastic stage of longitudinal reinforcements due to the development of concrete crack. (3) after the load $Q$, the $E$ ' increases sharply than before displaying a different tend to the previous one, which indicates that the RC box-girder turns into an unstable stressing state from the stable stressing state.

Therefore, the characteristic load $P$ can be seen as the demarcation point from elastic working state to plastic working state. When the steel bars or concrete is partly in plastic stage, it may have limited effects on the change of structural stressing state because of the whole structure's self-adaption and self-adjustment. Thus, the structure still keeps in a stable performance until load $Q$. After the characteristic load $Q$, the development of plastic deformation accumulates to a certain extent, which results in the mutation of structural stressing state with faster growth of $E$, according with the natural law from quantitative change to qualitative change of a system. The characteristic load $Q$ is defined as failure load, which could be seen as the termination of the previous stable stressing state of the $\mathrm{RC}$ box-girder. Also, it could be regarded as the starting point of the structural destroy process, leading to an updated definition of structural failure. Load $Q$ to the qualitative leap of the RC box-girder's stressing state, instead of the ultimate load at which the structure loses its bearing capacity, should be defined as the failure load of the RC box-girder. Therefore, the failure load $Q$ is different from the existing failure load defined at the structural ultimate load-bearing capacity $U$, which should be taken as reference to structural design load.

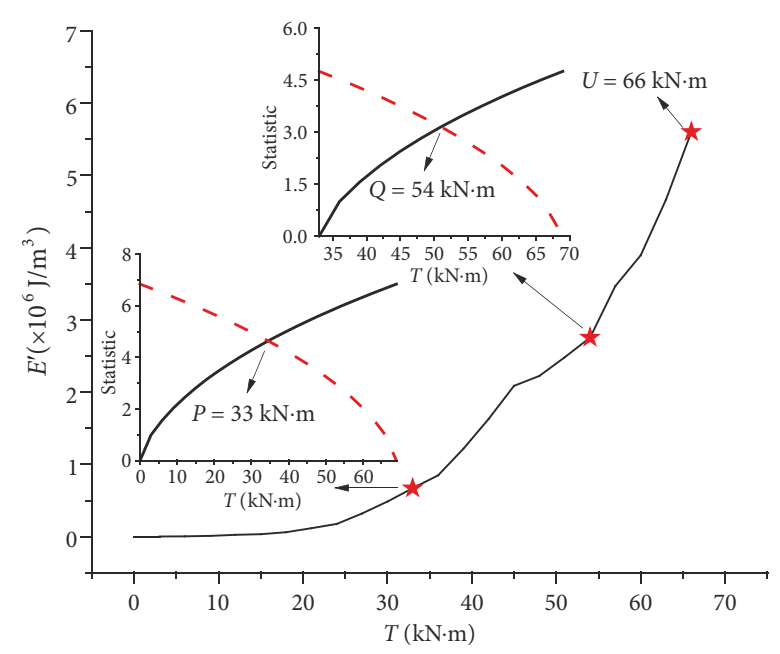

Figure 4. $E^{\prime}-T$ and M-K statistic curves of RC box-girder numbered B4 


\subsection{Analysis of structural stressing state mode}

According to the loading scheme mentioned above, the mid-span cross section of experimental RC box-girder is the key section subjected to the combined action of bending and torsion and its $\mathrm{L} / 4$ cross section is the control section bearing the combined action of bending, shear and torsion. The strains of longitudinal reinforcements at midspan cross section and the strains of stirrups and CFRP at $\mathrm{L} / 4$ cross section are both recorded to construct structural stressing state mode. In fact, the strain of a point represents the stressing state of this point. Therefore, the structural stressing state mode can be formed as a vector through assembling the strains of measuring points, e.g., $\mathbf{S}_{\mathrm{ls}}=\left[e_{\mathrm{ls} 1}, e_{\mathrm{ls} 2}, \ldots, e_{\mathrm{ls} 7}\right]^{\mathrm{T}}$ for longitudinal reinforcements at mid-span cross section, $\mathrm{s}_{\mathrm{ss}}=\left[e_{\mathrm{ss} 1}, e_{\mathrm{ss} 2}, \ldots, e_{\mathrm{ss} 8}\right]^{\mathrm{T}}$ for stirrup at $\mathrm{L} / 4$ cross section and $\mathrm{s}_{\mathrm{cs}}=\left[e_{\mathrm{cs} 1}, e_{\mathrm{cs} 2}, \ldots, e_{\mathrm{cs} 8}\right]^{\mathrm{T}}$ for CFRP at $\mathrm{L} / 4$ cross section. Then, the $S_{\text {strain }}-T$ curves can be plotted to detect the changing features of stressing state mode $S_{\text {strain }}$ with load increase. Figure 5 shows the $S_{\text {stain }}-T$ curves of longitudinal reinforcement, stirrup and CFRP, respectively. The structural performance can be revealed through investigating the changing characteristics of constructed stressing state mode, given as:

- Before the first characteristic load $P$, longitudinal reinforcements, stirrup and CFRP are in elastic stage without yield, indicating that the RC box-girder's stressing state keeps stable. As shown in Figure 5, at the load $P$, the longitudinal reinforcement strain of point 4 just reaches to its yield strain with a great deal of stretch cracks on the bottom surface, resulting in the structural behavior turns from linear-elastic state to elastic-plastic state. From $P$ to $Q$, the $S_{\text {strain }}$ increases faster than the previous stage with the change of structural stressing state. After the load $Q$, the $S_{\text {strain }}$ further increases with the load. Therefore, the $S_{\text {strain }}-T$ curves reveal the leap characteristic at load $P$ and load $Q$ consisted with that distinguished by the $\mathrm{M}-\mathrm{K}$ method in Figure 4.

- In Figure 5(a), the longitudinal reinforcements of point 6 and point 7 at the upper part of mid-span cross section subject to the interaction of bending moment and torsion. The stress of point 6 and point 7 appear compression under bending moment and tension under torque, leading to low stress levels. Thus, the longitudinal reinforcements of point 6 and point 7 always keep in elastic working state until the structural destroy. While the remaining longitudinal reinforcements successively reach to yield stage after the load $P$. In Figure 5(b), the stirrup strain measured at the $\mathrm{L} / 4$ cross section bears the combined action of bending-shear-torsion. The stirrup strain of point 3 is far greater than the other points' strains because the shear caused by torsion has the same direction with the original shear at point 3 .

- In Figure 5(c), the longitudinal strain of CFRP is the largest among these four measuring locations' strains from initial loading to final failure of the RC box- girder, stating the longitudinal CFRP pasted in the soleplate plays a significant role in bearing the loads. In addition, Figure 5(c) also demonstrates the reinforcement effects of different CFRP sticking position, which can further provide the rational strengthening scheme.

Meanwhile, the structural stressing state mode can also be expressed through the other form of $\mathrm{S}_{\text {strain }}-T$ curves. As shown in Figure 6, the leap characteristic of structural performance can also be confirmed, which is consistent with the law revealed in Figure 5. After the load Q (dashed lines), the strains of stirrups and CFRP increase sharply
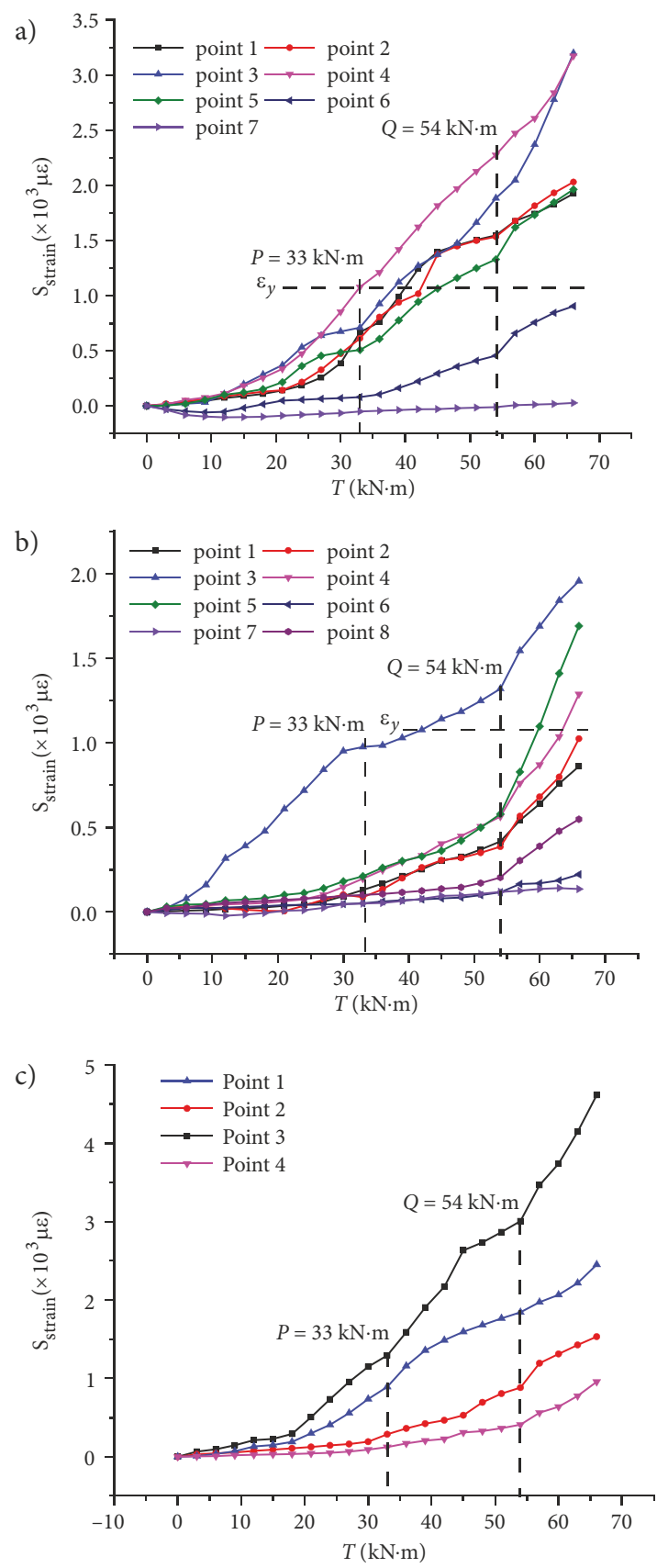

Figure 5. The strain-based stressing state mode with the increasing load: a - the $S_{\text {strain }}-T$ curves for longitudinal reinforcement; $b$ - the $S_{\text {strain }}-T$ curves for stirrup; $c-$ the $S_{\text {strain }}-T$ curves for CFRP 
than previous stage, indicating a mutation occurs in the structural stressing state mode at failure load ascertained by the $\mathrm{M}-\mathrm{K}$ criterion. Therefore, the increment of strains with the increasing load reveals the leap features at the characteristic load $Q$. And the increment of strains can be used as the corresponding parameter to characterize the stressing state mode $S_{\text {strain }}$.
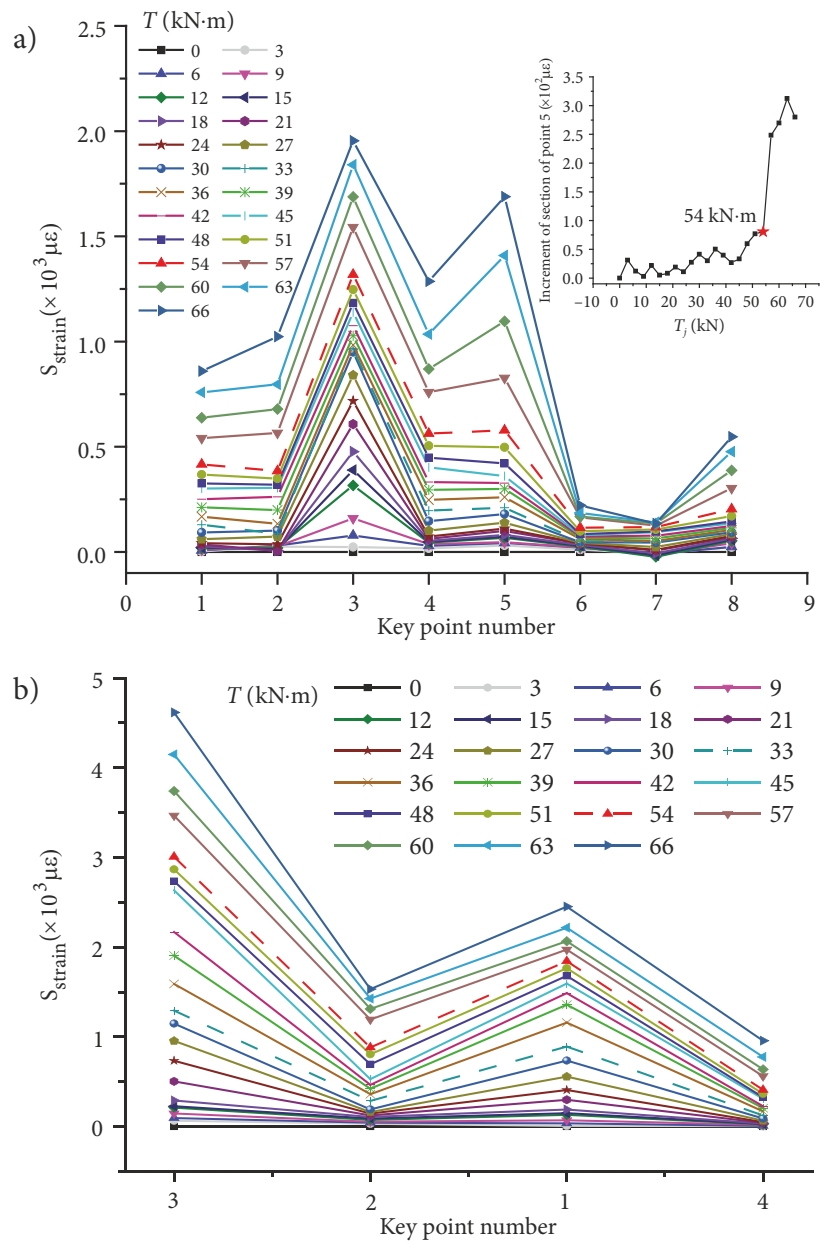

Figure 6. The changing features of strain-based stressing state mode: $\mathrm{a}$ - the pattern of stressing state mode for stirrup at $\mathrm{L} / 4$ cross section; $\mathrm{b}$ - the pattern of stressing state mode for CFRP at $\mathrm{L} / 4$ cross section

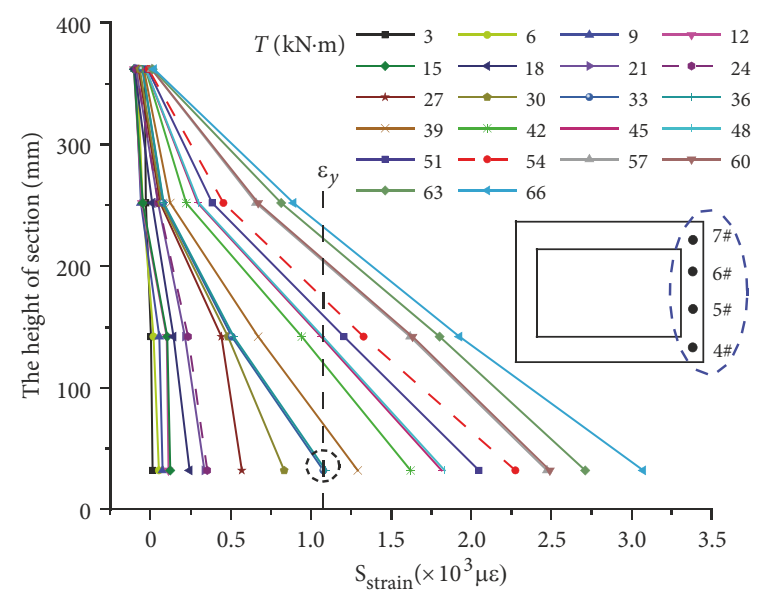

Figure 7. Location-strain curves of mid-span cross section

\subsection{Characteristic of stressing state mode for plane-section}

In order to investigate the changing process of sectional working features under the combined action of bending moment and torsion, the strains of longitudinal reinforcements along the height of mid-span section are constructed the sectional stressing state mode, $\mathbf{S}_{j}=\left[s_{4 j}, s_{5 j}, s_{6 j}, s_{7 j}\right]^{\mathrm{T}}$, in which $j$ is load step and the $s_{4 j}, s_{5 j}$, $s_{6 j}$ and $s_{7 j}$ are the strains of measuring points under the $j$-th load. As shown in Figure 7, the strain of longitudinal reinforcement at the lower part of the section increases much faster than that at the upper part of the section. Before $24 \mathrm{kN} \cdot \mathrm{m}$, the strains at these four measuring points are basically in a straight line, indicating the mid-span cross section maintains flat state during this load-bearing stage. After $24 \mathrm{kN} \cdot \mathrm{m}$, the strain of longitudinal reinforcement at the bottom of RC box-girder increases sharply as a result of the intensive development of concrete crack. But the longitudinal reinforcements are not yielded in the stretch area until load $P$, the increment of strain is limited which reflects a basic flat state although emerging a slight nonlinear state. After the characteristic load $P$, the upper longitudinal reinforcements also gradually put in plastic yield state with large amount of plastic deformation, resulting in a non-flat state. When the load exerts the load $Q$, it can be seen from the Figure 7 that a leap characteristic occurs in the flat state of the mid-span cross section. After the characteristic load $Q$, the strains at these four measuring points are in a straight line again, stating the load is mainly subjected by longitudinal reinforcements and the concrete almost loses its bearing capacity due to the sufficient development of concrete cracks. The structural stressing state changes from stable to unstable. Hence, it is reasonable to define the load $Q$ as the failure load, revealing the leap characteristic of the RC box-girder's stressing state mode.

\section{Experimental study on the box-girders with different CFRP wrapping schemes}

\subsection{The $E^{\prime}-T$ curves of different CFRP wrapping schemes}

From the perspective of GSED, this paper investigates the effects of CFRP on box-girders' performance after strengthening, the $E^{\prime}-T$ curves of these five experimental specimens are plotted in the same graph, as shown in Figure 8. Through comparative analysis, there are almost no distinction among the entire $E^{\prime}-T$ curves before $27 \mathrm{kN} \cdot \mathrm{m}$, indicating the reinforcement effects of CFRP is not sufficiently exerted and the behavior of tested RC boxgirders strengthened with CFRP has few differences with the controlled RC box-girder without wrapping CFRP. After $27 \mathrm{kN} \cdot \mathrm{m}$, the bifurcation phenomenon of $E^{\prime}-T$ curves become obvious, demonstrating CFRP gradually begins functioning due to the development of concrete cracks and the yield of steel bars with load increase. In addition, the failure loads of B1, B2, B3 and B5 are also determined 
through following the same path as proposed in Section 2, as listed in Figure 8. Generally speaking, the result shows the failure loads of RC box-girders strengthened with CFRP (B2, B3, B4, B5) are apparently enhanced than that of B1. Through comparing failure load and ultimate bearing capacity of the four different reinforcement schemes listed in Table 1, some research results can be concluded as follows:

- From the $E^{\prime}-T$ curve of B2 in Figure 8, the GSED value of $\mathrm{B} 2$ increases rapidly after the failure load, which can be attributed to the development of plastic deformation. Actually, the failure load can also be regarded as the characteristic load of reinforcement effect. That is, although the RC box-girder can still bear load after the failure load, the CFRP is unable to provide effective reinforcement for the tested boxgirder to keep a stable stressing state. In addition, since the failure load and ultimate load of B2 are the lowest among these four reinforced RC box-girders, the reinforcement effect of bottom configuration using full CFRP sheet is the weakest.

- The failure load of B4 is the same as that of B5 and larger than the failure loads of remaining RC boxgirders. Besides, the ultimate load of B4 is the largest among the four reinforced RC box-girders. Therefore, the U configuration using full CFRP sheets is the most effective reinforcement scheme, which can greatly improve the load bearing capacity of RC boxgirder.

- Because the B5 has larger failure load and ultimate load than those of B2, the reinforcement effects of RC box-girder with bottom configuration using full CFRP sheet and U configuration using separate CFRP strips at the same time is better than that of RC box-girder with only bottom configuration using full CFRP sheet. Similarly, both the failure load and ultimate load of B3 are larger than those of B2, indicating the CFRP wrapping scheme of $\mathrm{U}$ configuration using separate CFRP strips is more helpful to improve the performance of $\mathrm{RC}$ box-girder than the strengthening method of $\mathrm{B} 2$.

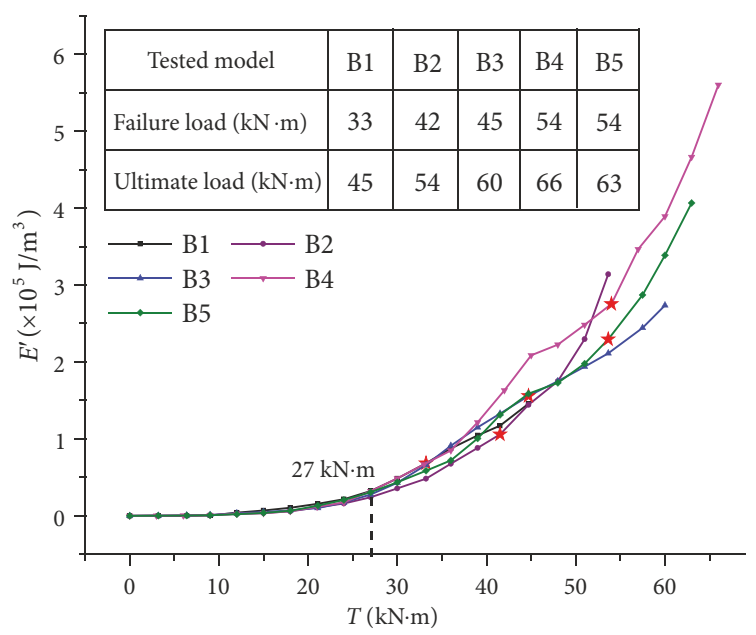

Figure 8. GSED-based analytical approach for RC box-girders with different wrapping schemes

\subsection{Investigation into the strain modes of stirrups}

Actually, the application of CFRP sheet at the bottom of RC box-girder can be regarded as longitudinal strengthened constrains for the tested box-girder, and using $U$ configuration with separate CFRP strips to strengthen RC
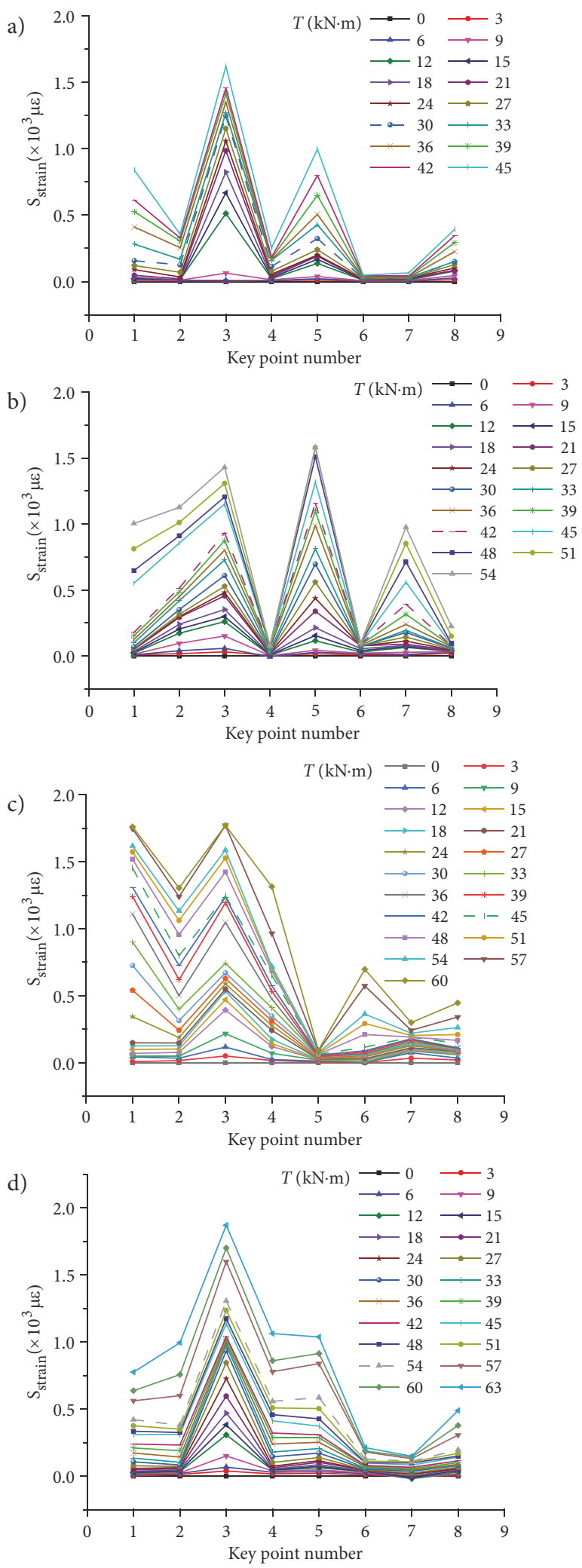

Figure 9. The strain distribution of stirrup for: $\mathrm{a}-\mathrm{B} 1 ; \mathrm{b}-\mathrm{B} 2 ; \mathrm{c}-\mathrm{B} 3$; d - B5 
box-girder can be seen as lateral restraint for the tested box-girder. Figure 9 shows the strain modes of stirrups at the measuring section of five experimental box-girders. And the dash lines in the figures are consistent with the failure loads determined above by M-K criterion. The leap characteristics under failure loads are clearly embodied in the corresponding strain modes of stirrups, indicating the stressing states of RC box-girders change greatly after failure loads and verifying the accuracy of RC box-girders' failure loads.

Through comparing B2 and B1, the strains of the middle measuring points $(1,3,5,7)$ located at each side of the rectangle hoop significantly increase after pasting full CFRP sheet at the bottom of box-girder. While the strains of measuring points near the corner of stirrup $(4,6,8)$ are much smaller than those of the middle measuring points. Hence, longitudinal strengthened constrains can further improve the strains in the middle of each side of stirrup, but the corners of stirrup make little contribution to resisting the interaction of torque and shear, showing the function of stirrup is not fully exerted. For B3 and B1, the reinforcement method of $U$ configuration with separate CFRP strips can obviously improve the strains of measuring points near the corner of stirrup $(2,4,6,8)$. Therefore, after applying lateral restraint to the box-girder with CFRP strips, the strain distribution model of rectangle hoop is similar to that of spiral hoop, indicating the rectangle hoop plays its full role against the load. For B4 and
B5, the value and distribution pattern of stirrup's strain at each measuring point is basically in generally agreement, which suggests that the effect of these two reinforcement methods on improving the behavior of RC box-girders is similar. However, the reinforcement scheme of $\mathrm{B} 5$ requires less CFRP, which is more economical and reasonable.

In order to investigate the characteristics of strain distribution from the perspective of strain level, Table 2 lists the number of measuring points in high/low strain levels. Generally speaking, the strains of measuring points from 1 to 5 tend to keep in high strain level while those of measuring points from 6 to 8 usually maintain low levels, due to the interaction of shear and torque. In addition, the quantities of measuring points in high strain level multiply after strengthened with CFRP, indicating the capacity of stirrup is fully exploited. Meanwhile, based on the strain distribution level of stirrup at the measuring section, the working situation of stirrup could be clearly understood, which may be applied to provide guidance for reinforcement design.

\subsection{The comparison of longitudinal reinforcements' strain modes between $B 1$ and $B 5$}

The effects of strengthening with CFRP on the performance of RC box-girder can also be reflected in the strain modes of longitudinal reinforcements. Figure 10 shows the strain modes of B1 and B5, respectively. Through comparing these two graphs, some conclusions can be summarized.

Table 2. Distribution of the strain level at measuring points of RC box-girders

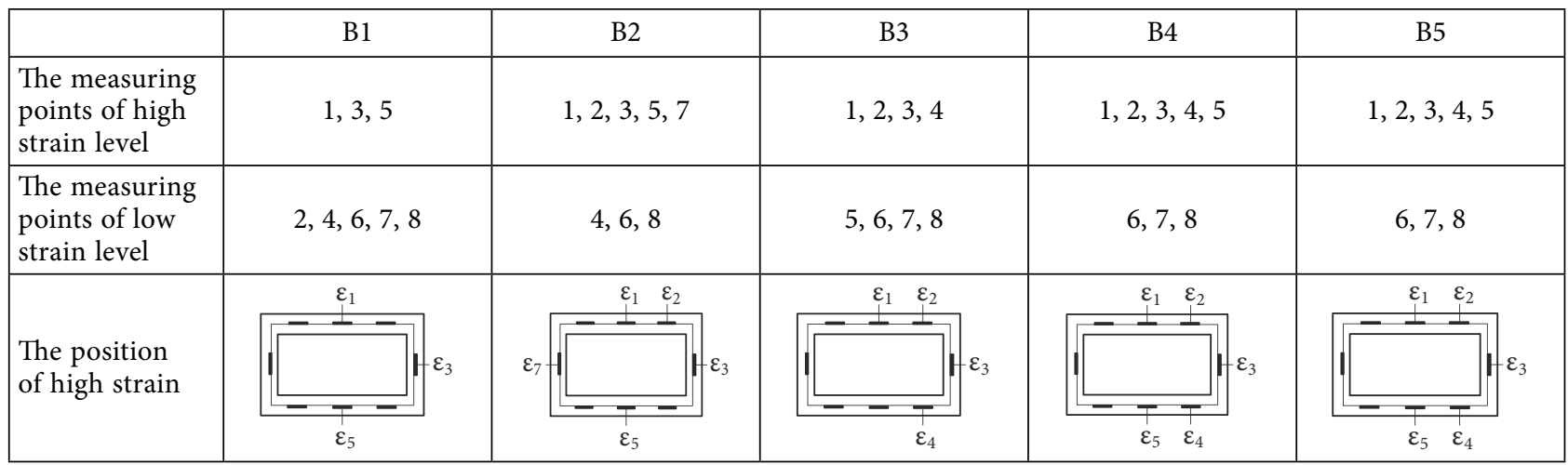

a)

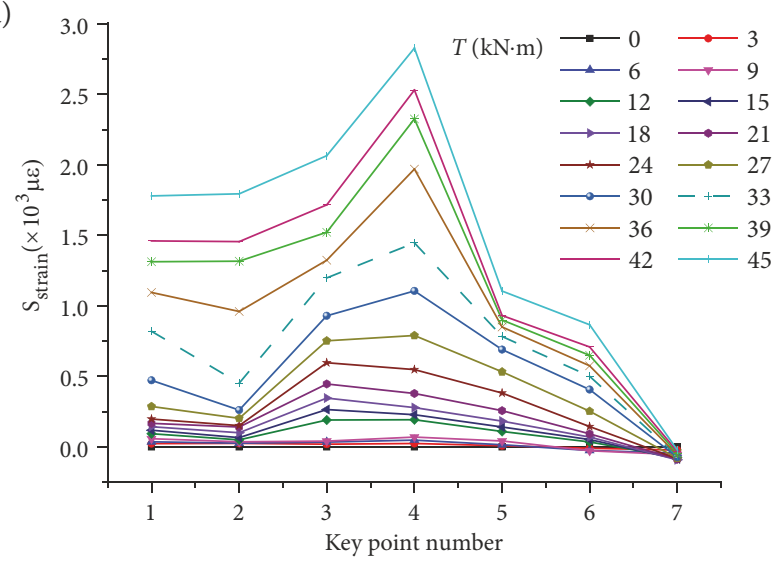

b)

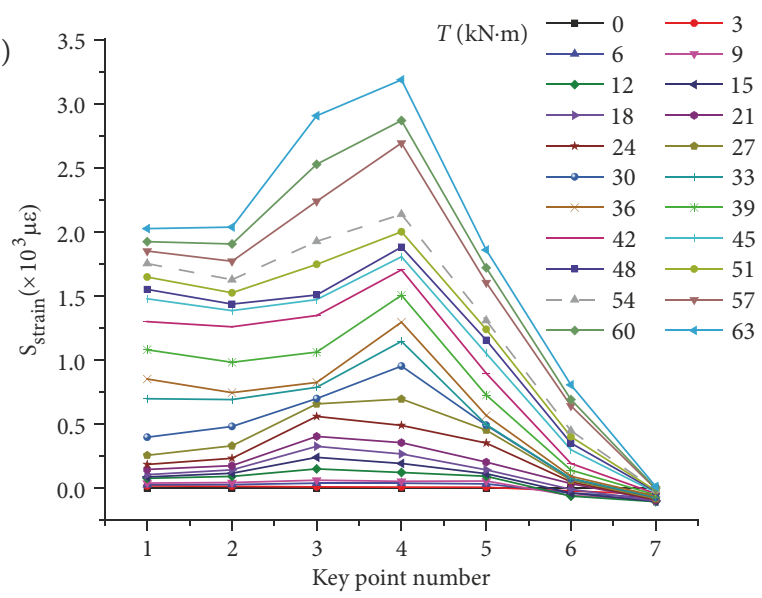

Figure 10. The strain distribution of longitudinal reinforcements for: $\mathrm{a}-\mathrm{B} 1 ; \mathrm{b}-\mathrm{B} 5$ 
Firstly, after failure loads (dash lines), the strains of measuring points present sharp increase in trend whether strengthened with CFRP or not. Therefore, the stressing state mutation characteristics are also well embodied in the strain modes of longitudinal reinforcements. Secondly, from the Figure 10(a) and (b), the strains at point 4 are the largest, indicating the longitudinal reinforcement at the bottom corner of box-girder's section plays a significant role in resisting torsion. In addition, the strain difference of B5 among point 1,2, 3, 4 and 5 is smaller than that of $\mathrm{B} 1$, reflecting the outstanding coordinate working behavior among longitudinal reinforcements after strengthened with CFRP.

\section{The application of numerical shape function in stressing state analysis of box-girders}

\subsection{The method of numerical shape function}

Numerous space interpolation methods (SIMs) have been proposed to predict the experimental data at unsampled points using the limited experimental data at measuring points (S. Andersen \& L. Andersen, 2010). However, the estimation accuracy of common SIMs is difficult to achieve the desired objectives as a result of ignoring the invisible information between spatial distribution and numerical values of samples. In addition, redundant assumptions on the mathematical models and corresponding parameters also restrict the engineering application of SIMs (Li \& Heap, 2011). Therefore, in order to improve the interpolation accuracy, Shi, Zheng, Tan, Yang, and Zhou (2019) combined the numerical simulation with experimental data and proposed numerical shape function (NSF) interpolation method. The construction process of NSF is given as:

- As shown in Figure 11(a), for the finite element (FE) model of specimen's cross section, Shell 181 element is adopted for concrete, its thickness is $5 \mathrm{~mm}$ and has an area of $10 \times 10 \mathrm{~mm}^{2}$. Beam 188 element is used for longitudinal reinforcement. Its area takes the actual area of longitudinal reinforcement, and its thickness is $5 \mathrm{~mm}$. Beam 188 element is also used for CFRP in the simulation of cross section. Its length takes the value of the side length of wrapped box-girder, its thickness is also $5 \mathrm{~mm}$. In addition, the connection between reinforcement and concrete is assumed to be rigid. There are 14 measured strain values in the cross section as samples.

- Through applying displacement $d=1$ at the $i$-th measuring points and $d=0$ at other points, the shape function $N_{i}$ of measuring points $i$ can be derived from $\mathrm{FE}$ simulation. Its form is $\mathbf{N}_{i}=$ $\left[N_{i}\left(x_{1}\right), N_{i}\left(x_{2}\right) \cdots N_{i}\left(x_{j}\right) \cdots N_{i}\left(x_{n}\right)\right]$, where $\mathrm{N}_{i}\left(x_{j}\right)$ is the simulated value at element node $x_{j}$ and $n$ is the total node of the plate. As a result, Figures 11(b) and 11(c) show the shape function of $\mathbf{N}_{1}$ and $\mathbf{N}_{4}$, respectively. a)

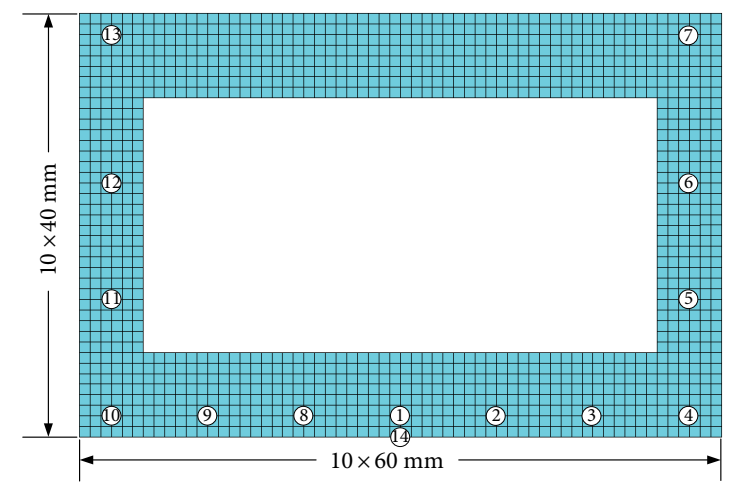

b)

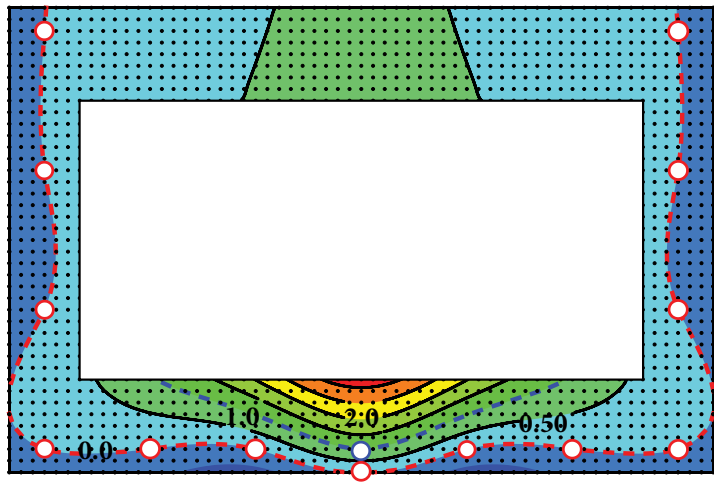

c)

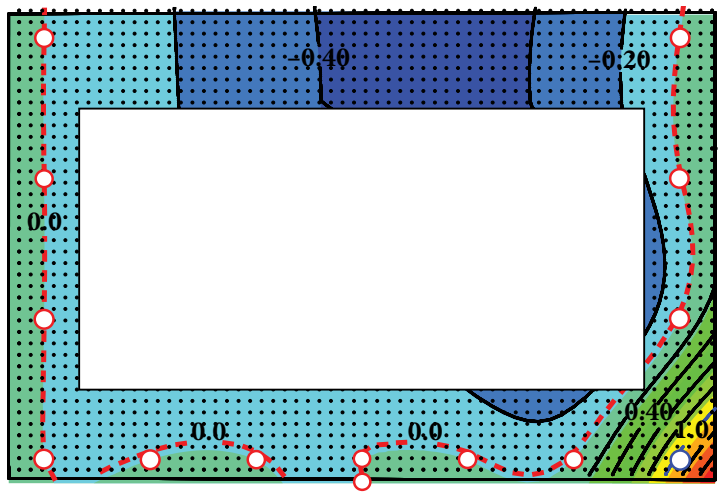

Figure 11. Finite element model and contour map of numerical shape function: $\mathrm{a}$ - finite element model; $\mathrm{b}$ - shape function $\mathbf{N}_{1} ; \mathbf{c}$ - shape function $\mathbf{N}_{4}$

- The interpolated field of cross section model can be calculated by the linear combination of NSFs obtained above, as follows:

$\mathbf{D}=\sum_{i=1}^{m} u_{i} \mathrm{~N}_{i}$

where $\mathbf{D}$ is the interpolated field of the plate; $u_{i}$ is the measuring samples; $m$ is the total number of measuring points and it is 14 in this case.

\subsection{Investigation into the characteristics of strain fields}

The middle section of box-girder is meshed through FE method. Then the strain fields can be obtained by interpolating the measured strains based on the NSF method. As shown in Figure 12, the strain contour maps of B1 and 
B1
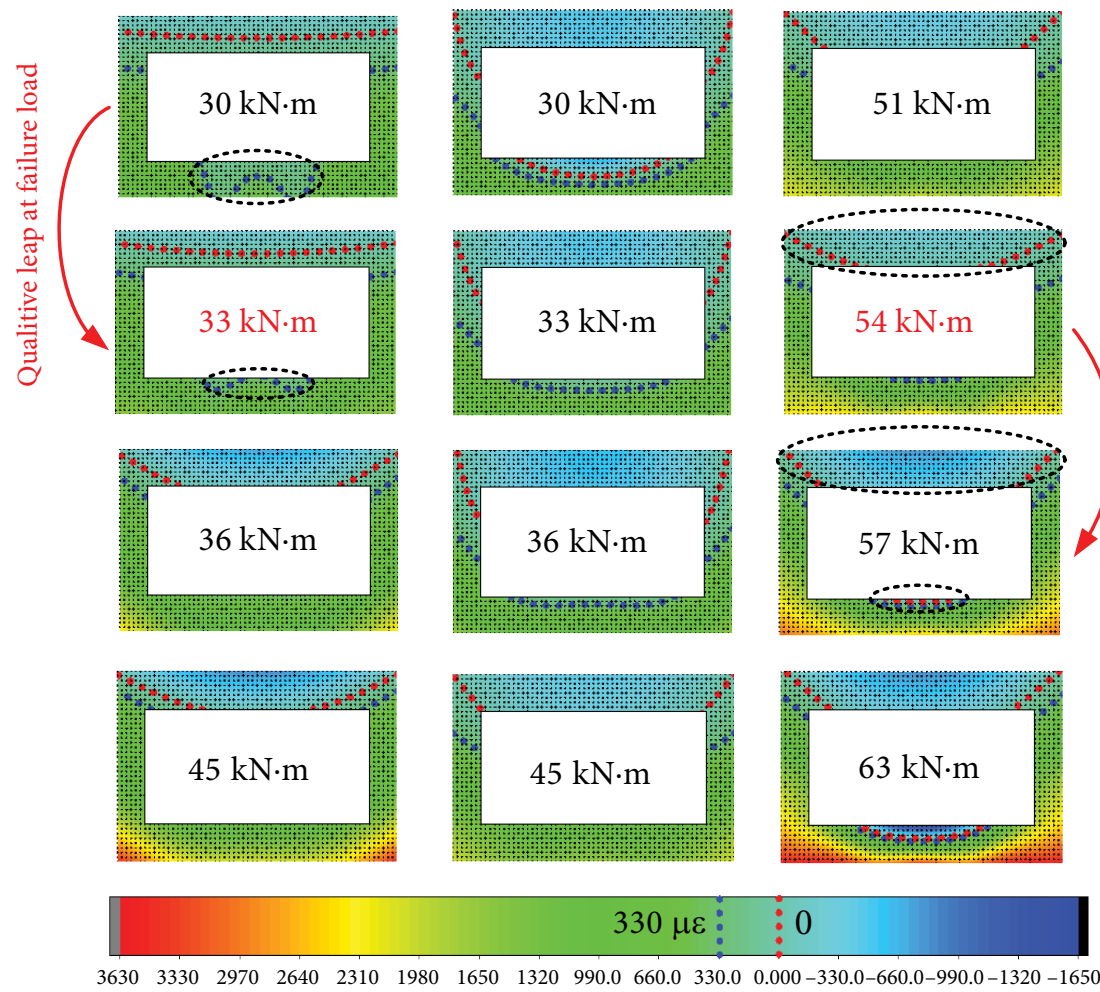

Strain $\mu \varepsilon$

B5
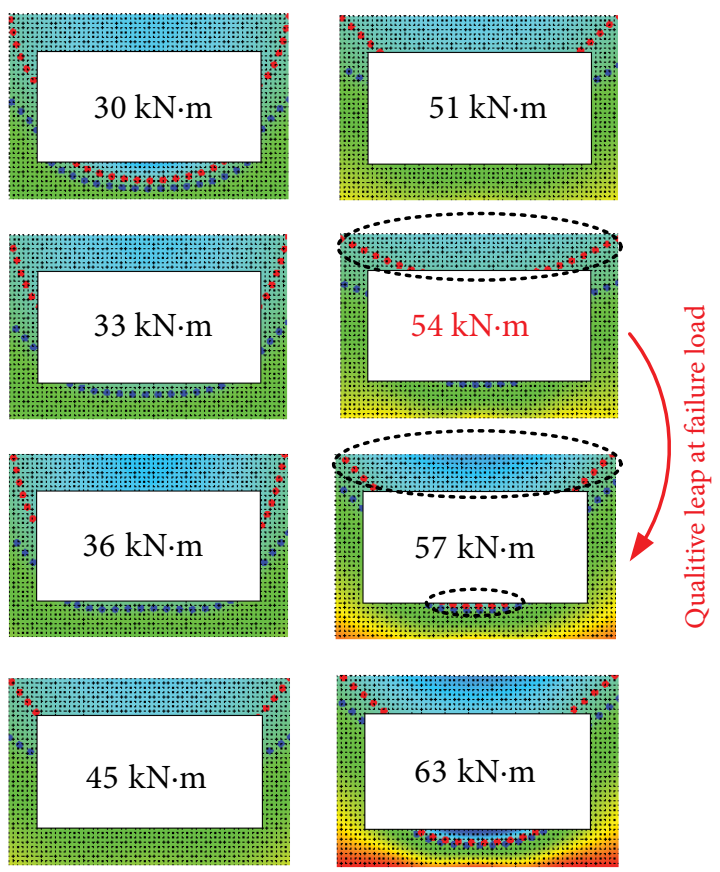

Figure 12. The strain contour maps of B1 and B5
B5 around their respective failure loads and ultimate loads are demonstrated. Moreover, the contour maps of B1 and B5 at the same load level are also plotted to facilitate the contrast analysis. In the contour maps with the same color scale, the separatrix of $0 \mu \varepsilon$ is marked with red dotted line to intuitively observe the distribution of tensile and compressive region. The separatrix of $330 \mu \varepsilon$ (ultimate tensile strain) is marked with blue dotted line. The concrete below the blue dotted line can be considered to lose its bearing capacity since the strain exceeds the ultimate tensile strain. It can be seen from Figure 12 that the strain data of all the strain field keep are symmetrical, which is consist with the loading condition. For B1, the region beyond ultimate tensile strain expands largely and the compressive part also increases rapidly before and after 33 $\mathrm{kN} \cdot \mathrm{m}$, indicating a qualitative leap at failure load. For B5, after $54 \mathrm{kN} \cdot \mathrm{m}$, the concrete cracks fully develop and the CFRP plays its full role in improving the performance of box-girder. For instance, the CFRP pasted in the bottom of experimental box-girder sustains tension like longitudinal reinforcement, resulting in an increasing height of compression zone.

Through comparing the strain contour maps of B1 and B5 from $30 \mathrm{kN} \cdot \mathrm{m}$ to $45 \mathrm{kN} \cdot \mathrm{m}$, the effects of CFRP reinforcement can be revealed as follows:

- At the same load level, the depth of compression of B5 is larger than that of B1, indicating the compression resistance of concrete can be fully utilized after wrapping with CFRP.
- The area beyond ultimate tensile strain of B5 is less than that of B1, illustrating CFRP reinforcement can effectively restrict the development of concrete and improve the behavior of box-girder.

\section{Conclusions}

An experimental investigation is carried out on one unreinforced RC box-girder and four RC box-girders strengthened with different CFRP wrapping schemes. Structural stressing state theory and methodology are applied to reveal tested box-girders' invisible behavior characteristics hidden in the measured strain data. The qualitative leap characteristics of box-girders' stressing state are detected by $\mathrm{M}-\mathrm{K}$ criterion, which updates the definition of structural failure load. And the rationality is verified through analyzing the changing trends and distribution patterns of stressing state modes.

Based on the strain distribution patterns of stirrups and longitudinal reinforcements, this paper also studies the effect of four CFRP wrapping schemes on the mechanical performance of box-girder subjected to the combined action of bending, shear and torsion. Although all these reinforcement methods can enhance the experimental box-girders' failure load and ultimate load, their effects on the performance of box-girders are distinguishable to some extent. For box-girders strengthened with $U$ configuration (B3, B4, B5), the shear contribution of stirrup is fully developed, even the measuring points at the corner 
of stirrup show large strain. On the other hand, for the box-girder with bottom-pasted CFRP (B2), the strain of measuring point located at the middle of each side of stirrup is further improved while that at the corner of stirrup is in a lower level.

The NSF method is applied to reasonably expand the limited strain data to further explore the changing features of section strain field, which can also reveal the qualitative leap characteristic of stressing state characteristics. Meanwhile, compared with the contrast box-girder, the effect of CFRP reinforcement on the strain distribution of cross section can be observed vividly.

Applying the stressing state theory to the measured experimental data, the achieved results reveal stressing state characteristics of box-girders. The reinforcement effects of four CFRP wrapping schemes on the experimental RC box-girders are investigated based on the theory of structural stressing state, providing appropriate reference for structural reinforcement.

\section{Acknowledgements}

This work was financially supported by the National Natural Science Foundation of China (Grant Nos. 51608069). The authors would like to express their gratitude to Gaofei Yang for carrying out the excellent RC box-girders experiment and giving the experimental data in detail in his dissertation thesis. The authors are grateful to all members of the HIT 504 office for their selfless help and useful suggestions.

\section{Funding}

This work was supported by the National Natural Science Foundation of China under Grant [number 51608069].

\section{Author contributions}

Shi Jun and Xiao Hengheng conceived the study and were responsible for the design and development of the data analysis. Liu Junran and Shi Jun were responsible for data collection, analysis and interpretation. Xiao Hengheng and Zheng Kaikai helped perform the analysis with constructive discussions. Xiao Hengheng wrote the first draft of the article.

\section{Disclosure statement}

All the authors have no conflict of interest.

\section{References}

Aidoo, J., Harries, K. A., \& Petrou M. F. (2004). Fatigue behavior of carbon fiber reinforced polymer-strengthened reinforced concrete bridge girders. Journal of Composites for Construction, 8(6), 501-509.

https://doi.org/10.1061/(ASCE)1090-0268(2004)8:6(501)

Aidoo, J., Harries, K. A., \& Petrou, M. F. (2006). Full-scale experimental investigation of repair of reinforced concrete in- terstate bridge using CFRP materials. Journal of Bridge Engineering, 11(3), 350-358.

https://doi.org/10.1061/(ASCE)1084-0702(2006)11:3(350)

Ali, N., Samad, A. A. A., Mohamad, N., \& Jayaprakash, J. (2013). Shear behaviour of pre-cracked continuous beam repaired using externally bonded CFRP strips. Procedia Engineering, 53, 129-144. https://doi.org/10.1016/j.proeng.2013.02.019

Al-Mahaidi, R., \& Hii, A. K. Y. (2007). Bond behaviour of CFRP reinforcement for torsional strengthening of solid and boxsection RC beams. Composites Part B (Engineering), 38(5-6), 720-731. https://doi.org/10.1016/j.compositesb.2006.06.018

Al-Zaid, R. A., El-Sayed, A. K., Al-Negheimish, A. I., Shuraim, A. B., \& Alhozaimy, A. M. (2014). Strengthening of structurally damaged wide shallow RC beams using externally bonded CFRP plates. Latin American Journal of Solids and Structures, 11(6), 946-965.

https://doi.org/10.1590/S1679-78252014000600003

Andersen, S., \& Andersen, L. (2010). Analysis of spatial interpolation in the material-point method. Computers \& Structures, 88(7-8), 506-518.

https://doi.org/10.1016/j.compstruc.2010.01.004

Barnes, R. A., \& Mays, G. C. (1999). Fatigue performance of concrete beams strengthened with CFRP plates. Journal of Composites for Construction, 3(2), 63-72.

https://doi.org/10.1061/(ASCE)1090-0268(1999)3:2(63)

Bousselham, A., \& Chaallal, O. 2013. Experimental investigations on the influence of size on the performance of RC Tbeams retrofitted in shear with CFRP fabrics. Engineering Structures, 56, 1070-1079.

https://doi.org/10.1016/j.engstruct.2013.06.028

Esfahani, M. R., Kianoush, M. R., \& Tajari A. R. (2007). Flexural behaviour of reinforced concrete beams strengthened by CFRP sheets. Engineering Structures, 29(10), 2428-2444. https://doi.org/10.1016/j.engstruct.2006.12.008

Fagone, M., \& Ranocchiai, G. (2018). Experimental investigation on out-of-plane behavior of masonry panels strengthened with CFRP sheets. Composites Part B (Engineering), 150, 1426. https://doi.org/10.1016/j.compositesb.2018.05.031

Foster, R. M., Brindley, M., Lees, J. M., Ibell, T. J., Morley, C. T., Darby, A. P., \& Evernden, M. C. (2016). Experimental investigation of reinforced concrete T-beams strengthened in shear with externally bonded CFRP sheets. Journal of Composites for Construction, 21(2), 04016086. https://doi.org/10.1061/(ASCE)CC.1943-5614.0000743

Hii, A. K. Y., \& Al-Mahaidi R. (2007). Torsional capacity of CFRP strengthened reinforced concrete beams. Journal of Composites for Construction, 11(1), 71-80.

https://doi.org/10.1061/(ASCE)1090-0268(2007)11:1(71)

Hirsch, R. M., Slack, J. R., \& Smith, R. A. (1982). Techniques of trend analysis for monthly water quality data. Water Resources Research, 18(1), 107-121. https://doi.org/10.1029/WR018i001p00107

Huang, Y., Zhang, Y., Zhang, M., \& Zhou, G. (2014). Method for predicting the failure load of masonry wall panels based on generalized strain-energy density. Journal of Engineering Mechanics, 140(8), 04014061. https://doi.org/10.1061/(ASCE)EM.1943-7889.0000771

Jiang, H., Zhang, T. P., \& Tian, L. Q. (2018). Review of FRP reinforced damaged RC beams. Low Temperature Architecture Technology, 40(9), 64-66.

Kendall, M. G. (1957). Rank correlation methods. Biometrika, 44, 298. https://doi.org/10.2307/2333282

Leung, C. K. Y., Chen, Z., Lee, S., Ng, M., Xu, M., \& Tang, J. (2007). Effect of size on the failure of geometrically similar 
concrete beams strengthened in shear with FRP strips. Journal of Composites for Construction, 11(5), 487-496. https://doi.org/10.1061/(ASCE)1090-0268(2007)11:5(487)

Li, J., \& Heap, A. D. (2011). Review of comparative studies of spatial interpolation methods in environmental sciences: Performance and impact factors. Ecological Informatics, 6(30), 228-241. https://doi.org/10.1016/j.ecoinf.2010.12.003

Mann, H. B. (1945). Nonparametric tests against trend. Econometrica, 3(3), 245-259. https://doi.org/10.2307/1907187

Nair, A., Cai, C. S., Kong, X., \& Hou, S. (2019). Bridge retrofitting using FRP-wrapped balsa wood deck: Experimental study and field evaluation. Journal of Aerospace Engineering, 32(5), 04019065. https://doi.org/10.1061/(ASCE)AS.1943-5525.0001057

Orbanich, C. J., Dominguez, P. N., \& Ortega, N. F. (2012). Strengthening and repair of concrete foundation beams with carbon fiber composite materials. Materials and Structures, 45(11), 1693-1704. https://doi.org/10.1617/s11527-012-9866-6

Pham, H., \& Al-Mahaidi, R. (2004). Experimental investigation into flexural retrofitting of reinforced concrete bridge beams using FRP composites. Composite Structures, 66(1-4), 617625. https://doi.org/10.1016/j.compstruct.2004.05.010

Rafi, M. M., Nadjai, A., Ali, F., \& Talamona, D. (2008). Aspects of behaviour of CFRP reinforced concrete beams in bending. Construction and Building Materials, 22(3), 277-285. https://doi.org/10.1016/j.conbuildmat.2006.08.014

Rahai, A. R., \& Saberi, M. R. (2011). Experimental and numerical investigation of damaged concrete beams strengthened with FRP composed of different fibres and resins. Structural Design of Tall and Special Buildings, 20(8), 972-985. https://doi.org/10.1002/tal.570

Samad, A. A. A., Ali, N., Mohamad, N., Jayaprakash, J., Tee, K. F., \& Mendis, P. (2017). Shear strengthening and shear repair of 2-span continuous RC beams with CFRP strips. Journal of Composite for Construction, 21(3), 04016099. https://doi.org/10.1061/(ASCE)CC.1943-5614.0000756
Shahawy, M. A., Arockiasamy, M., Beitelman, T., \& Sowrirajan, R. (1996). Reinforced concrete rectangular beams strengthened with CFRP laminates. Composites Part B Engineering, 27(3-4), 225-233. https://doi.org/10.1016/1359-8368(95)00044-5

Shi, J., Li, W. T., Zheng K. K., Yang, K., \& Zhou, G. (2018). Experimental investigation into stressing state characteristics of large-curvature continuous steel box-girder bridge model. Construction and Building Materials, 178, 574-583. https://doi.org/10.1016/j.conbuildmat.2018.05.155

Shi, J., Zheng, K. K., Tan, Y. Q., Yang, K., \& Zhou, G. (2019). Response simulating interpolation methods for expanding experimental data based on numerical shape functions. Computers \& Structures, 218, 1-8. https://doi.org/10.1016/j.compstruc.2019.04.004

Yang, D. S., Park, S. K., \& Neale, K. W. (2009). Flexural behaviour of reinforced concrete beams strengthened with prestressed carbon composites. Composite Structures, 88(4), 497-508. https://doi.org/10.1016/j.compstruct.2008.05.016

Yang, G. F. (2016). Research of CFRP reinforced concrete box girder bending shear and composite stress (MS thesis). Lanzhou Jiaotong University (in Chinese).

Zhou, G. C., Rafiq, M. Y., Bugmann, G., \& Easterbrook, D. J. (2006). Cellular automata model for predicting the failure pattern of laterally loaded masonry wall panels. Journal of Computing in Civil Engineering, 20(6), 400-409. https://doi.org/10.1061/(ASCE)0887-3801(2006)20:6(400)

Zhu, J. T., Wang, X. L., Kang, X.-D., Li, K. (2016). Analysis of interfacial bonding characteristics of CFRP-concrete under fatigue loading. Construction and Building Materials, 126, 823-833. https://doi.org/10.1016/j.conbuildmat.2016.06.071 